\section{Tracheal paraganglioma}

\author{
A P Gallimore, P Goldstraw
}

\begin{abstract}
The trachea is an unusual site for paragangliomas, only four cases having been documented previously. A fifth case is presented here, together with immunohistochemical evidence that the tumour is biologically benign.
\end{abstract}

(Thorax 1993;48:866-867)

\section{Case history}

A 55 year old woman presented with a 12 month history of intermittent haemoptysis. During this time chest radiographs showed only transient abnormality-right lower lobe collapse-which cleared after expectoration of some blood clot. Two attempts at fibreoptic bronchoscopy failed before she proceeded to bronchoscopy under general anaesthesia. At bronchoscopy a vascular, polypoid tumour, $3 \mathrm{~cm}$ in diameter, was seen arising from a broad base from the anterior wall of the trachea just proximal to the carina. A biopsy specimen of the tumour was taken, accompanied by brisk haemorrhage, and the tumour was later removed by a segmental tracheal resection through a right thoracotomy. Postoperative recovery was uneventful and there has been no recurrence 12 months after resection of the tumour.

\section{Pathological findings}

The resection specimen consisted of a segment of trachea which contained a fleshy, sessile tumour arising from the anterior wall. Blocks from the tumour were fixed in $10 \%$ formal saline, processed, embedded in paraffin wax, and $5 \mu \mathrm{m}$ sections were cut.

Department of
Histopathology,
University College and
Middlesex Hospital
School of Medicine,
London WC1E 6JJ
A P Gallimore
Department of
Cardiothoracic
Surgery, Royal
Brompton National
Heart and Lung
Hospital, London
SW3 6NP
P Goldstraw
Reprint requests to:
Dr A P Gallimore
Received 14 July 1992
Returned to authors
16 September 1992
Revised version received
22 September 1992
Accepted 24 September 1992

Figure 1 Nests of type 1 cells surrounded by type 2 sustentacular cells. Haematoxylin and eosin.

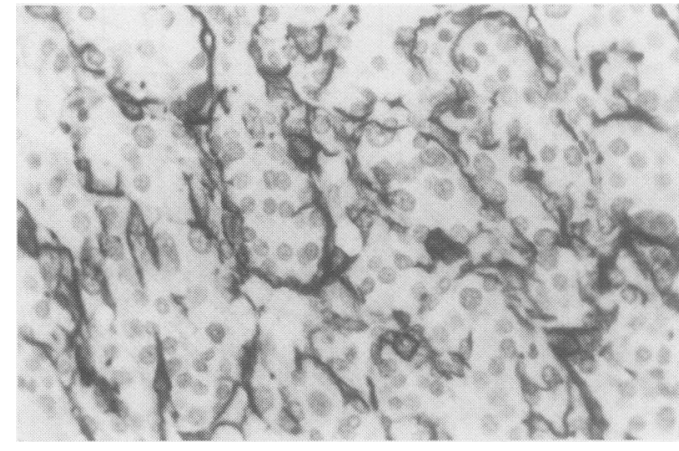

Figure 2 Immunostaining with GFAP highlighting the peripheral type 2 cells.

The sections were stained with haematoxylin $\underset{\substack{\infty \\ \infty}}{\stackrel{\infty}{\infty}}$ and eosin and reticulin.

Immunohistochemical examination was $\stackrel{\circ}{\circ}$

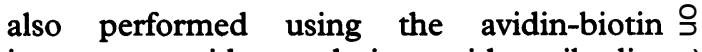
immunoperoxidase technique with antibodies to high (LP 34) and low (CAM 5.2) molecular weight keratins, S100 protein, glial fibrillary acidic protein (GFAP), neurone specific enolase (NSE), chromogranin, and synaptophysin.

The histological appearance was of a well circumscribed, unencapsulated tumour composed of nests of uniform tumour cells within

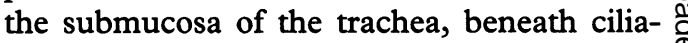
ted columnar respiratory epithelium. The $\stackrel{\AA}{\varrho}$ nests contained chief cells (type 1) with pale $\overrightarrow{\overrightarrow{0}}$ granular, eosinophilic cytoplasm, mildly pleo- 3 morphic nuclei with inconspicuous nucleoli and sustentacular cells (type 2) at the periphery (fig 1). The latter were elongated and possessed scanty cytoplasm. There was no evidence of mitotic activity, necrosis, or vascular invasion. Anteriorly the tumour was pushing between the rings of tracheal cartilage into the pretracheal connective tissues. Reticulin stain highlighted the nesting pattern of the tumour.

Immunohistochemical examination showed $\frac{7}{2}$ strong cytoplasmic reactivity in the chief cells for NSE, chromogranin, and synaptophysin. Sustentacular cells stained positively for both $N$ S100 and GFAP (fig 2). Both type 1 and type $\underset{\mathcal{N}}{\mathcal{N}}$ 2 cells were negative for high and low molec- $\square$ ular weight keratin.

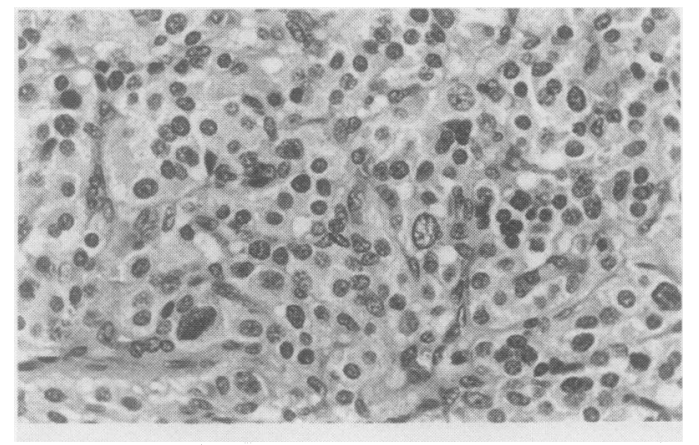

\section{Discussion}

Tracheal paragangliomas are rare neoplasms $\frac{0}{\infty}$ and only four cases have been reported previ- $\stackrel{\circ}{\circ}$ ously. ${ }^{1}$ The origin of these tumours is $\stackrel{\mathbb{2}}{2}$ unclear, origination from true tracheal or ectopic paraganglial tissue having both been 8 postulated. $^{23}$ The finding of paraganglia in? normal human trachea validates the plausibil-ôे ity of the former suggestion. ${ }^{2}$ Laryngeal para- $?$ gangliomas, which may be supraglottic or subglottic, are also rare but rather more common than tracheal tumours. Their origin 
from either supraglottic and subglottic laryngeal paraganglia is not disputed.

In one of the previously reported cases of tracheal paraganglioma massive bleeding accompanied surgical removal and the patient died perioperatively. ${ }^{4}$ Although this was a large tumour extending from vocal cord to carina, there was no evidence of malignancy.

The three other cases have behaved in a benign fashion. ${ }^{135}$ Evidence has recently been collected that the presence of sustentacular cells positive for $\mathrm{S} 100$ and GFAP is a marker for a benign lesion and, specific ally, that they are not found in malignant lesions. ${ }^{6}$ It has also been shown that GFAP positive cells are found only in parasympathetic paragangliomas. ${ }^{7}$

The immunohistochemical findings in this case confirmed that the tumour was a para- ganglioma derived from parasympathetic paraganglia and suggest that benign clinical behaviour is to be expected.

1 Liew S-H, Leong AS-Y, Tang HMK. Tracheal paraganglioma: a case report and review of the literature. Cancer 1981;47:1387-93.

2 Lawson W, Zak FG. The glomus bodies ("paraganglia") of the human larynx. Laryngoscope 1974;83:98-111.

3 Zeman MS. Carotid body tumour of the trachea. Glomus jugularis tumour, tympanic body tumour, nonchromaffin paraganglioma. Ann Otol Rhinol Laryngol 1956;65: $960-2$

4 McCall JW, Karam FK. Chemodectoma of the trachea. Arch Otolaryngol 1958;67:372-3.

5 Horree WA. An unusual primary tumour of the trachea (chemodectoma). Pract ORL 1963;25:125-6.

6 Kliewer KE, Wen D-R, Cancilla PA, Cochran AJ Paragangliomas: assessment of prognosis by histologic, immunohistochemical, and ultrastructural techniques. Hum Pathol 1989;20:29-39.

7 Achilles E, Padberg B-C, Holl K, Kloppel G, Schroder S Immunohistochemistry of paragangliomas: value of staining for $\$ 100$ protein and glial fibrillary acid protein in diagnosis and prognosis. Histopathology 1991;18:453-8.

Thorax 1993;48:867-868

\title{
Pleural effusions associated with pancreaticopleural fistula
}

S G J Williams, A Bhupalan, N Zureikat, P J Thuluvath, G Santis, N Theodorou, D Westaby

\begin{abstract}
Two cases of pancreaticopleural fistula are reported. The delay in diagnosis and extensive investigations performed highlight the need for pleural fluid amylase estimation at an early stage.
\end{abstract}

(Thorax 1993;48:867-868)

Department of

Gastroenterology,

Charing Cross

Hospital, Fulham

Palace Road, London

W6 8RF

$S$ G J Williams

A Bhupalan

N Zureikat

P J Thuluvath

N Theodorou

D Westaby

Department of

Respiratory Medicine,

Royal Brompton

National Heart and

Lung Hospital,

Sydney Street,

London

SW3 6NP

G Santis

Reprint requests to:

Dr D Westaby

Received 21 July 1992

Returned to authors

16 September 1992

Revised version received

12 October 1992

Accepted 16 October 1992
Pancreaticopleural fistula is an uncommon cause of large, recurrent, predominantly left sided pleural effusions. When the underlying pancreatic disease is asymptomatic the diagnosis may not be considered and, as a consequence, extensive unnecessary investigations may ensue. We report two cases in which long delays in diagnosis (four and 13 months) of the pancreaticopleural fistula occurred. These cases emphasise the importance of considering the diagnosis and of estimating the pleural amylase content.

\section{Case 1}

A 50 year old man presented to another hospital with exertional dyspnoea and a four month history of weight loss. There was no previous history to suggest pancreatic disease but he drank 40 units of alcohol per week.

Examination indicated a large left sided pleural effusion which was confirmed by

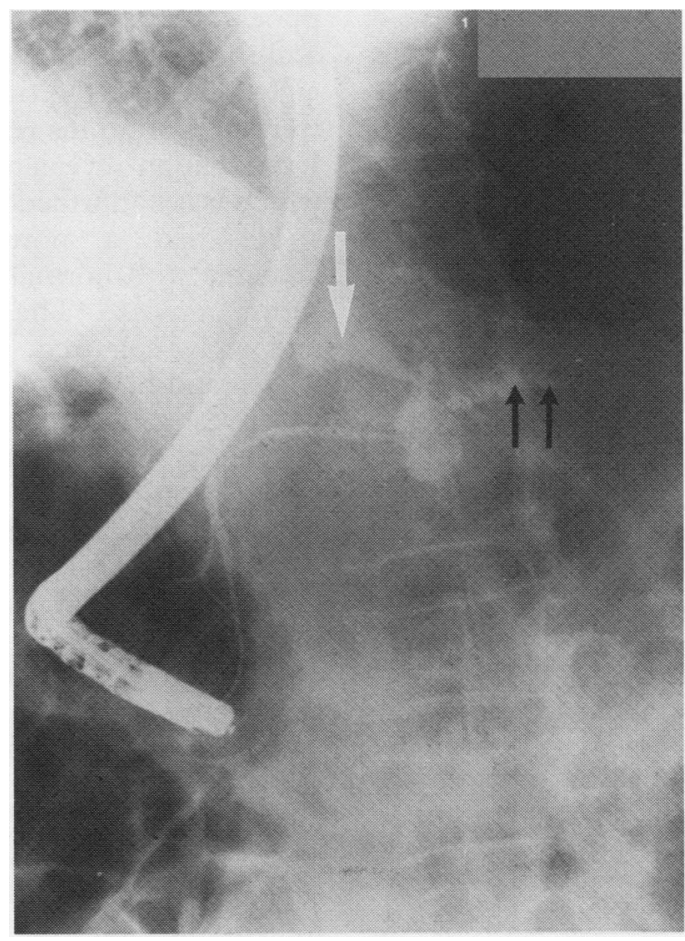

Endoscopic retrograde pancreatogram showing a dilated pancreatic duct (black arrows) distal to a mid duct stricture. A clear leak of contrast from the pancreas can be seen arising from the strictured area tracking towards the pleura (white arrow). Selective cannulation of the pancreatic duct to the level of the stricture was required to show these findings.

chest radiography. The pleural fluid had a protein content of $87 \mathrm{~g} / 1$ and both cytological and microbiological investigations were negative. The pleural biopsy specimen was normal, as were the results of bronchoscopic examination. A computed tomographic (CT) scan of the chest revealed thickening of the left hemidiaphragm, and a CT scan of the abdomen revealed left para-aortic lymphadenopathy. Ultrasound guided biopsy of the lymph nodes showed reactive changes only. A bone marrow aspirate and trephine sample were normal. 